Max-Planck-Institut für demografische Forschung

Max Planck Institute for Demographic Research

Doberaner Strasse $114 \cdot$ D-18057 Rostock $\cdot$ GERMANY

Tel +49 (0) 3812081 - 0; Fax +49 (0) 3812081 - 202;

http://www.demogr.mpg.de

MPIDR WORKING PAPER WP 2002-016

APRIL 2002

\title{
How Premarital Children and \\ Childbearing in the Current Marriage \\ Influence Family Stability
}

Liu, Guiping (liu@demogr.mpg.de)

This working paper has been approved for release by: Jan M. Hoem (hoem@demogr.mpg.de)

Head of the Laboratory of Contemporary European Fertility and Family Dynamics.

(C) Copyright is held by the authors.

Working papers of the Max Planck Institute for Demographic Research receive only limited review. Views or opinions expressed in working papers are attributable to the authors and do not necessarily reflect those of the Institute. 
How Premarital Children and Childbearing in the Current Marriage Influence Family Stability

--Descriptive findings based on Swedish register data

Liu, Guiping

Max-Planck-Institute for Demographic Research

Doberaner Strasse 114, Rostock, Germany

Phone: +493812081189

Fax: $\quad+493812081489$

liu@demogr.mpg.de

20 April 2002 


\begin{abstract}
:
By using a Swedish register data set and applying hazard models with unobserved heterogeneity, this study demonstrates that childbearing history plays an important role in predicting the divorce risks of families with various types of premarital children. Families with premarital children definitely have a higher risk of divorce than do those without premarital children. Producing a common child cements bonds in the family but as the youngest common child grows up, his or her role of maintaining family relations weakens. Families with premarital children from the wife's relation with another man clearly have a higher risk of divorce than do families with other types of premarital children. Additional findings deviate from what has been reported in the literature.
\end{abstract}

Key words: divorce risk, premarital children, common childbearing, stepfamily, Sweden 


\section{Introduction}

The existence of premarital children may complicate family relationships. They also make the study of family instability more complicated. No wonder, therefore, that the literature is as well contradictory. In applying the concept of 'marriage-specific capital' to explain family instability in second and later marriages, Becker, Landes and Michael (1977) maintained that 'children (and perhaps other specific capital) from previous marriages could reduce the stability of the current marriage because they are a source of friction'. White and Booth (1985) claimed that the presence of stepchildren is a destabilizing influence in late remarriages and a major contributor to their somewhat greater rate of divorce. Similarly, Furstenberg (1990) concluded that because of the ambiguity of family norms and because bonds between stepparents and their children are weaker and sometimes fraught with conflict, relationships in stepfamilies are generally less harmonious and gratifying. In fact, both Cherlin and Furstenberg have paid much attention to the high instability of American stepfamilies since the late 1970s. Cherlin (1978) proposed the term incompletely institutionalized' family to explain the high rates of separation and divorce of remarriage families in the United States. Furstenberg described a 'distinctively different family form' in 1979 and in 1984, proposed the term 'the new extended family' in 1987 (for an overview, see Cherlin \& Furstenberg, 1994).

One may assume that having common children can improve a remarried couple's relationships with each other because common children provide closer ties between the parents. In contrast, Ganong and Coleman's (1988) investigation implies 
that having common children does not really cement bonds within families, but they only focus on the changing ties among family members instead of dealing directly with divorce risks of families.

Using the National Longitudinal Survey of Youth (NLSY) and applying a joint modeling procedure, Upchurch, Lillard and Panis (2001) found no direct effect of non-marital children on the risk of dissolution. They claimed that 'non-marital children appear to delay women's marriage formation, but once married, the nonmarital children do not contribute to the risk of separating'. They drew their conclusions after accounting for the 'endogeneity' of the multiple processes.

Some existing research based on Swedish data shows that women who have premarital children have an excess risk of divorce in their first marriage (Hoem, 1995; Hong, 1996; Andersson, 1997; Liu, 2002). Yet this research does not show how different definitions of premarital births influence the divorce risk of families, because 1) it does not focus on how stepchildren affect the risk of divorce and 2) no such suitable data was available at that time. Others have tried to figure out why mothers with stepchildren have a higher risk of divorce and have hypothesized that 'the remaining excess risk of divorce for mothers of premarital stepchildren may stem from the fact that their husband are not these children's biological fathers' (Qvist et al. 1995, Andersson, 1997). This argument remains unproved.

With a newly structured register data set from Statistics Sweden, this study tries to answer three questions. First, does having premarital children in fact lead to an excess risk of divorce? Second, how do various compositions of children born before the current marriage formation influence family instability? Third, does the 
presence of common births cement bonds in the family? We focus only on the empirical evidence, and leave further theoretical explanations for another time..

\section{Data \& Method}

\subsection{Data}

For our hazard analysis of the divorce risks of Swedish women in their first marriage, we use a unique set of Swedish individual-level register data with ample information on demographic profiles and on social and economic characteristics. The data set contains records for both men and women. It covers the period from 1945 through 1999. We include seven covariates in our models, namely the composition of premarital children of various parenthood, the woman's age at first marriage, the woman's parity, an indicator of pregnancy at marriage formation, an indicator of the woman's pregnancy in the current marriage, an indicator of childbearing after the current marriage formation, and the age of the youngest common child. The woman's age at first marriage, the indicator of woman's pregnancy in the current marriage and the age of the youngest common child are straightforward and are readily obtained from the raw data set. A woman's parity can be easily obtained when the parenthood of premarital children and the indicator of common childbearing have been established. (A woman's parity is defined as the number of children she has produced).

We now explain how we got the rest of the variables from the raw data set.

The Swedish Register Database contains separate records for each individual. The record contains the individual's ID number and date of birth as basic information, and has other related information (educational attainment, annual 
income, employment status, information on marriage and divorce, childbearing history and so on). A woman's record contains the birth dates of all her children, their ID numbers, and the ID number of her husband or partner's ID number. In a man's record, we have the same information but no information about his children is available. Rather, children are related to men via women's records. In a child's record, we have the date of birth, the biological mother's ID number, and the biological father's ID number. By comparing the ID numbers of a child's biological father with the ID number of the mother's present partner (husband), we obtain complete information about motherhood and fatherhood. This is to say that we know whether any child is a stepchild to any of the parents in this family and whether he/she is a biological child to any of the parents, or to both parents. We also know whether any child was born before the current marriage (premarital children) because we know the date of marriage. In Sweden, it is not unusual that a woman already has children when she marries. A premarital child could have a father other than the mother's current husband, or a common child who is produced by the current couple before the marriage formation in which case it is the spouses' common child.

We define a fixed covariate called 'the type of premarital children' according to the different possibilities of parenthood. A description of the types of premarital children is summarized in Table 1. It is an inherent weakness of our data that we have no information on non-marital cohabitation. In most cases, a woman's children live with her. If her current husband has children with other women, those children usually live with their biological mothers. In any case, we do not account for children's residence in our analysis, only for their parenthood.

(Table 1 near here) 
We have also constructed a couple of related variables. We use the number of common children born in the current marriage as a time-varying variable. In addition, we include the separate numbers of the various types of premarital children as time-invariant covariates. On this basis, we have introduced an indicator of childbearing in the current marriage as another time-varying covariate.

We have also constructed another time-invariant covariate, namely, an indicator of pregnancy at marriage formation, based on some reasonable judgments. Given the birthday of a child in the current marriage, we estimated the beginning of a known pregnancy by counting seven months backward from the date of the child's birth. (We assume that a woman becomes certain of her pregnancy about two months after conception.) If the date of a woman's known pregnancy is earlier than the date of her marriage, we assume that the woman knew she was pregnant at marriage. Since we have the ID number of the child's biological father, we also know whether the mother's husband is the child's biological father. Therefore, we know whether the mother was pregnant with a stepchild to her husband when she married him. This mainly lets us see to what degree her husband, tolerated her pregnancy from another man, and we can study its effect on the subsequent marital dissolution risks.

A simplified childbearing history of the couple is indicated in the last panel of Table 2. It is an interaction of the type of premarital children with the indicator that a woman is currently pregnant, the age of the youngest common child and an indicator of common childbearing in the current marriage. The immense Swedish registers allow us to make such a luxurious segmentation of data that leads to some interesting and unusual findings. 
The time variable of our hazard analysis is the duration of the first marriage. We include 'only' women who got married between January of 1980 and December of 1998. Observations are censored after 15 years of marriage, at the emigration of the man or the woman, at the death of the spouse, and at the end of 1998.

\subsection{Method}

We used an intensity regression model, seen below, to determine the risk of divorce in the first marriage:

$$
\begin{aligned}
\ln \mu_{i}(t)=y(t)+\alpha_{1} \text { MarAge } & +\alpha_{2} \text { WParity }+\alpha_{3} \text { PregMarl } \\
& +\boldsymbol{\alpha}_{4} \text { PreKidType } * \text { NewKids } * \text { PregMar } 2 * \text { YChildAge }+v_{i} ;
\end{aligned}
$$

where $t$ is the duration since marriage formation;

$\mu_{i}(t)$ is the intensity of divorce at duration $t$ for individual $i$;

$y(t)$ is the baseline log-hazard;

$\alpha_{i}, i=1,2,3$, are parameters to be estimated;

$\boldsymbol{\alpha}_{4}$ is a vector of parameters to be estimated;

MarAge is the age at first marriage of the woman (fixed variable);

WParity is the total number of children that woman has produced (time-varying variable);

PregMarl is an indicator of pregnancy at marriage (fixed variable);

PreKidType is a vector of indicators of types of premarital children (fixed variable);

NewKids is an indicator that the spouses have common children

in the current marriage (time-varying variable);

Pregmar2 is an indicator that the woman is pregnant

in the current marriage (time-varying variable);

YChildAge is the age of the youngest common child of the couple (time-varying variable); $v_{i}$ captures woman-specific unobserved heterogeneity. 
To clarify any confounding effect of a woman's parity, we also run a model where the parity interacts with other covariates including the type of premarital children, the indicator of common childbearing after the current marriage formation, the indicator of a woman's pregnancy and the age of the youngest child. Because the forms of the two models are rather similar, we do not list the form of the second model here. The results received after running the second model are listed on Table 3.

Age at marriage is categorized into four groups, namely, 16-19, 20-23, 29-35, and 36-49 years. Age group 24-28 is the omitted reference group. Age of the youngest common child is categorized into 5 groups, namely, below 1 year, 1-2 years, 3-5 years, 6-8 years, and 9 years or older. We have used grouped versions of our continuous variables because they facilitate interpretation. We specify a residual component in the model to capture any unobserved heterogeneity. The observation unit in the data set is a woman, therefore the unobserved-heterogeneity component in the model captures woman-specific heterogeneity, as we noted above.

\section{Findings}

We first describe Table 2, showing the results from the first model where women's parity does not interact with other variables. Subsequently, we present Table 3, showing the results where woman's parity interacts with others. We call the results on Table 2 preliminary findings because we have not accounted for the interactive role of women's parity at that stage. 


\subsection{Preliminary findings}

The woman's age at first marriage is 'only' a control variable and, as usual, the divorce risk declines as this age increases. At this preliminary stage, the woman's parity is also regarded as a control variable.We find that, according to the level of divorce risks, women who remained childless or who produced only one child can be classified as one group, and women who produced two or more children can be classified as another. We also concluded that women who produced three children have a similar level of divorce risks as women who have produced four or more. The basic trend is that divorce risk decreases as the number of children in a family increases.

As expected, women who were pregnant with a baby of the current union at the time of marriage formation had a much lower risk of divorce than that of women about to give a birth to a stepchild to her husband. Women who were not pregnant at marriage had the lowest risk of divorce. Pregnancy at marriage raised the risks of divorce regardless of the couple's parenthood.

We turn now to the covariates of most interest to us; they are in the last panel of Table 2.

(Table 2 near here)

The lower panel of Table 2 is the result of the interaction among the type of premarital children, an indicator of common childbearing after the current marriage formation, and an indicator of woman's pregnancy and the age of the youngest common child. One sees that it consists of two sets of columns, namely, a single column for families with no common child born in the current marriage, and then a set for families with common children born. In the latter set, one finds the relative 
risks of divorce for women at pregnancy and with the youngest common child at various ages.

In the first column of the lower panel of Table 2, we find that families with premarital children of c-type show the lowest relative risk of divorce. In the second column, families with premarital children and where the woman was pregnant with a common child show the lowest relative risk of divorce. In the rest of the columns, all other families with various types of premarital children show a higher risk of divorce than that of those without premarital children. Put other way, in the lower panel of Table 2, the relative risks displayed on the top of each column are always the smallest, except in the first two columns, where the second figures are the smallest. Producing common children before marriage formation also leads to a higher risk of subsequent divorce.

We also note that producing common children after the current marriage was formed lowered the risk of divorce for all types of families. Relative risks on Table 2 show that families where the couple did not produce common children in the current marriage had very high risk of divorce. But as the youngest common child grew, say, to age three, the families with premarital children of $\mathrm{c}-\mathrm{w}-\mathrm{m}$-mixture again experienced a higher risk of divorce. This could stem from the fact that as children grow up, conflict tends to occur within families.

Table 2 further suggests that families in which the wife had premarital children have particularly high risks of divorce. We see this from three comparisons. First, families with w-type premarital children have a higher risk of divorce than do those with m-type premarital children. Second, families with a c-w-mixture of premarital children have a much higher risk of divorce than do those with c-m- 
mixture premarital children. Third, families with a w-m-mixture of premarital children have a much higher risk of divorce than do those with a c-m-mixture of premarital children. This finding is so robust that it holds for families that do/do not have a common child in the current marriage, and also for those families where the wife was pregnant with the spouses' common child. It also holds true regardless of the youngest common child's age.

Remember that premarital children of w-type are produced through the mother's relation with another man. They usually live with their mother, and may have a harder time getting along with their stepfather and their half-siblings. As a result, they may cause much friction in the family. Another reason may be that men are much less tolerant of stepchildren than women are. Men may be more concerned about their own children. The families with premarital children of a w-m-mixture and where the couple did not produce common children after they got married had the highest risk of divorce. This could be because there are no common children to serve as 'cement bonds', and conflict could be caused by the premarital children from both the wife's and husband's side.

Figure 1a based on Table 2 gives us a clearer understanding of the finding. The stippled blue line stands for the relative divorce risks of families with no premarital children. It is located in the lowest part of the field, showing the lowest relative risks of divorce. The curve for families with premarital children of c-type is just above the one for those families with no premarital children. This important point confirms that having children common to the current union before the marriage formation could also cause a higher risk of subsequent divorce than having no premarital children. The next is the curve for families with premarital children of $\mathrm{m}$ - 
type, and the curve further above is one for families with premarital children of c-mmixture. The four curves smoothly move up one above another. The curves for families with premarital children of w-type, c-w-type, w-m-mixture, and c-wmixture, however, make a great leap, implying substantially higher risks of divorce for these families. After the youngest common child turned three years old, families with premarital children of c-w-m-mixture had a higher risk of divorce than did those families with premarital children of w-m-mixture. Most of the curves show a decreasing risk of divorce as the age of the youngest common child reached 3 years or older.

(Figures $1 \mathrm{a}$ and $1 \mathrm{~b}$ near here)

Figure $1 \mathrm{~b}$ displays the same table panel from a different angle. It confirms further what we have pointed out above. First, a woman's pregnancy with a common child clearly avoided the marriage dissolution, no matter what kind of premarital children the spouses had before the current marriage formation. Second, when the youngest common child turned 3 years or older, the age of the youngest child no longer influenced the pattern of divorce risk, the type of the premarital children became the dominant factor shaping the curves which represent the relative risk. Third, families with common children aged 3-8 years old had the highest risk of divorce, and when the youngest common child reached 9 years or older, the divorce risk tended to decrease. But for families with premarital children of c-w-m-mixture, the relative divorce risk reached a peak after the youngest common child reached 9 years or older. A possible reason may be that in such families, the older the children are, friction is more likely to occur. Fourth, the age of the youngest child barely had an impact on the divorce risk for families with premarital children of w-m-mixture-- 
in Figure 1b, the points representing the relative risks of such families comes close together. Fifth, Figure 1b also confirms that families in which the wife had premarital children who were not her husband's have particularly high risks of divorce. The curves go up from the left to the right part of the diagram field where the relative risks for families with premarital children of c-w-mixture, w-type, c-w-mixture and w-m-mixture are displayed.

\subsection{Does a woman's parity matter?}

In our discussion of Table 2, we have not really accounted for the fact that there is an overlap in the lower part of the table between a woman's parity and her status. For instance, if a family had premarital children of a c-w-m-mixture and the couple produced a new child, the woman had at least a parity of 3. By contrast, for families with premarital children of m-type there could be only one woman's biological child in such a family and woman's parity could be 1, if the couple subsequently produced a shared child. Therefore, figures in the lower panel of Table 2 are for women of different parities and our preliminary results have not accounted for this.

Ignoring the interaction with women's parity should not have harmed our findings. On the one hand, in Table 2, we see that divorce risks decreased when the woman's parity increased. Women who had produced two or more children had a much lower divorce risk than women who only had produced one child or had not yet produced a child. On the other hand, the figures in the lower panel of Table 2 show that families with premarital children of the c-w-m-mixture had a much higher divorce risk than did families with premarital children to the m-type, although the latter type of family could have only one child of the woman. Several other examples in Table 2 are similar. This suggests that the divorce patterns shown in Table 2 are 
determined mainly by the parenthood of the premarital children. Premarital children seem to overwhelmingly overshadow the effect of a woman's parity.

To make sure that this reasoning is convincing, we have run another model where the woman's parity interacts with the other variables that indicate childbearing histories. The results are listed in Table 3. We now mainly compare the divorce pattern of families where a woman had produced three or more children with the corresponding figures in Table 2. The reason is that families where the wife had produced at least three children could cover all sorts of families, as defined in Table 1, with various types of premarital children. Remember that one of the main objectives of this study is to disclose how various type of premarital children influence family stability. To help draw a conclusion, we have plotted Figure $2 \mathrm{a}$ and Figure $2 b$, each based on the figures of Table 3, and compare Figure $2 a$ with Figure 1a, as well as Figure $2 b$ with Figure $1 b$.

(Table 3 near here)

(Figures $2 \mathrm{a}$ and $2 \mathrm{~b}$ near here)

We note that for families where the woman had produced at least three children, we have exactly the same findings as described above. We ignored the interacting effect of a woman's parity. Figure 2a, like Figure 1a, displays a rather similar pattern of divorce risks, where woman's parity does not act as an interaction element. Families with no premarital children have the lowest risks of divorce among all kind of families. This conclusion does not change with the age of the youngest common child. One striking difference between Figure 1a and Figure $2 \mathrm{a}$ is that in Figure $2 \mathrm{a}$, after the youngest reached 3 years of age or older, families with premarital children of w-m- mixture and families with premarital children of c-w-m-mixture 
had almost the same pattern of divorce risk. In contrast, Figure 1a demonstrates that the two kinds of families still showed a differential pattern of divorce after the youngest common child was 5 years old or older. But the curve for families with premarital children of c-w-m-mixture crossed the curve for families with premarital children of w-m-mixture and was above the latter one. The reason is that Figure 1a contains those families where the wife had produced fewer children. (According to Table 2, families with woman's parity 0 and 1 had higher risks of divorce than those families with a parity of 2 or above).

The listed relative risk of divorce in Table 3 for families with various types of premarital children also shows that having common children after the current marriage formation substantially reduced the risk of subsequent divorce within the families. As the youngest common child grew beyond age 3, having common children no longer greatly reduced the divorce risk of the family. Figure $2 b$ shows a rather similar pattern of divorce, compared to Figure 1b. More specifically, the curves for children aged 3-5, 6-8 and 9 and older are very close to each other, implying that the age of the youngest common child did not significantly influence the risk of divorce after the youngest common child grew older. For families with premarital children of w-m-mixture, there was no great impact on the divorce risk. The other curves in Figure $2 \mathrm{~b}$ display similar patterns to Figure $1 \mathrm{~b}$. A preliminary finding that those families with premarital children on the woman's side were more problematic still holds true for families where the woman had produced three or more children.

We note other facts after making woman's parity an interaction factor. The curves on Figures $2 \mathrm{a}$ and $2 \mathrm{~b}$ are comparable to the curves in Figures $1 \mathrm{a}$ and $1 \mathrm{~b}$ in that 
all move downward to the bottom of the field. This results from the fact that Figures $1 \mathrm{a}$ and $1 \mathrm{~b}$ reflect the interruptions of families where the wife had only produced one child or had not produced a child yet (because such families are exposed to an excess high risk of divorce). Figure $2 \mathrm{a}$ and Figure $2 \mathrm{~b}$, on the other hand, are not interrupted by these factors. With regard to families with premarital children of w-type or w-mmixture, if the woman had produced at least three children before the current marriage formation and did not produce a child in the current marriage, then there would be an extremely high risk of divorce (with relative risks of 12 or 19 , respectively).

Figures $3 \mathrm{a}$ and $3 \mathrm{~b}$ show the divorce pattern of families where the woman had a parity of 2, and Figure 4 shows the divorce pattern of families where the woman had a parity of 1 . Neither contradicts our conclusions described above. But Figure $3 a$ shows a more regular "reversed U-shape-curve" of divorce risk. Divorce risk reached the peak when the youngest child was aged 3 to 5 , and decreased subsequently when the child became older. Figure 4 shows a similar trend but the information on parenthood is incomplete.

Having common children before the marriage formation also cements bonds in the family. This conclusion is supported by the following facts. Families with premarital children of c-type had the lowest risk of divorce out of all other families. Families with premarital children of c-m-mixture had a lower risk of divorce than those families with premarital children of m-type, and families with premarital children of c-w-mixture had a lower risk of divorce than those families with premarital children of w-type. This finding holds true in every table and figure throughout this paper. 


\section{Conclusion}

Our findings concerning the effect of premarital children and the pattern of divorce risks in first marriages hold true even after the number of children that a woman has produced is controlled for as an interaction factor in the model. Families with premarital children had higher risks of divorce than families with no premarital children. Having common children cemented bonds both before and after formation of the current marriage. Premarital children from a woman's relationship with another man made the families highly unstable. Premarital children to the man were much less important than premarital children to the woman. The age of the youngest common child plays a role in predicting family stability as well.

Acknowledgements: I thank Statistics Sweden for providing the data for this study. I am particularly grateful to Jan Hoem for his extensive comments and support throughout the whole process of this investigation. Thanks go to Jonathan MacGill, who did the programming to convert the raw data into the format needed for the aML software. I received helpful comments from Gunnar Anderson on an earlier draft of this paper. I would like to thank Elizabeth Zach and Susann Backer for their editing helps.

\section{Reference:}

[1]. Andersson, G. (1997). The Impact of Children on Divorce Risks of Swedish Women'. European Journal of Population 13/2: 109-145.

[2]. Becker, G.S., Landes, E. M., Michael, R. T. (1977). 'An Economic Analysis of Marital Instability'. The Journal of Political Economy 86/6: 1141-1188. 
[3]. Cherlin, A. (1978). 'Remarriage as an incomplete institution'. American Journal of Sociology 84/3: 634-650.

[4]. Cherlin, A. J., Furstenberg, Jr., F.F. (1994). 'Stepfamilies in the United States: A Reconsideration'. Annual Review of Sociology 20: 359-381.

[4]. Furstenberg Jr., F. F. (1990). 'Divorce and the American Family'. Annual Review of Sociology 16: 379-403.

[5]. Ganong L. H. and Coleman M. (1988). 'Do Mutual Children Cement Bonds in Stepfamilies?' Journal of Marriage and the Family 50: 687-699.

[6]. Hoem, J. M. (1995). 'Educational Capital and Divorce Risk in Sweden in the 1970s and 1980s'. Stockholm Research Reports in Demography No. 95. Stockholm University, Demography Unit.

[7]. Hong, Y. (1996). Patterns of Divorce Risk in the 1970s and 1980s for Swedish Women with a Gymnasium Education. Stockholm Research Reports in Demography No. 103. Stockholm University, Demography Unit.

[8]. Liu, G. (2002). Divorce risk of Swedish women in their first marriages -- two cohorts born in 1950 and 1960. Working Paper No.12. Max-Planck Institute for Demographic Research, Rostock, Germany.

[9]. Qvist, J., Uhlen, M., and Sjoeberg, I. (1995). 'Skilsmaessor och separationer: bakgrund och utveckling'. Statistics Sweden, Stockholm: Demografiska Rapporter 1995: 1 .

[10]. Upchurch, D. M., Lillard, L. A., Panis, C. W. A. (2001) The Impact of Nonmarital Childbearing on Subsequent Marital Formation and Dissolution'. Chapter in $\mathrm{Wu}$, Haveman, and Wolfe (Eds.), Out of Wedlock: Trends, Causes, and Consequences of Nonmarital Fertility. Russell Sage, New York. 
[11]. White, L. K., and Booth, A. (1985). The Quality and Stability of Remarriages: the Role of Stepchildren'. American Sociological Review 50/5: 689-698. 
Table 1. Types of premarital children in the current marriage

\begin{tabular}{lc}
\hline Descriptions & Symbols \\
\hline All Premarital children are the husband's with other women & m-type \\
All premarital children are the wife's with other men & w-type \\
There are some premarital children of each kind above & w-m-mixture \\
All premarital children are common to the wife and husband & c-type \\
$\begin{array}{l}\text { Some of the premarital children are common to the wife and } \\
\text { husband, other are husband's with other women }\end{array}$ & c-m-mixture \\
Some of the premarital children are common to the wife and \\
husband, others are wife's with other men \\
Premarital children consist of c-type, w-type and m-type \\
\hline
\end{tabular}


Table 2. Relative risks of divorce of Swedish women in first marriages

Hazard model with unobserved heterogeneity

age at marriage of woman

\begin{tabular}{ll}
\hline $16-19$ & 7.97 \\
$20-23$ & 2.69 \\
$24-28$ & 1.00 \\
$29-35$ & 0.48 \\
$36-49$ & 0.23 \\
woman's parity (the total number of children that woman has produced) & \\
0 & 0.99 \\
1 & 1.00 \\
2 & 0.50 \\
3 & 0.38 \\
4 \& higher & 0.43
\end{tabular}

indicator of woman's pregnancy at marriage formation

not pregnant at marriage formation

Pregnant with child of the current union

Pregnant with stepchild to the husband

childbearing history of the spouses no common children born in the current marriage

no premarital children types of premarital children c-type

m-type

c-m-mixture

c-w-mixture

w-type

c-w-m-mixture

w-m-mixture
1.00

1.66

4.87

.69

1.00

.48

0.99

1.00

38

43

common children born in the current marriage

\begin{tabular}{lllllll}
\multicolumn{8}{c}{\begin{tabular}{l}
\multicolumn{6}{c}{ age of the youngest child (years) } \\
woman \\
pregnant
\end{tabular}} & below 1 & $1-2$ & $3-5$ & $6-8$ & $\begin{array}{l}\text { 9 \& } \\
\text { above }\end{array}$ \\
0.05 & 0.04 & 0.15 & 0.33 & 0.34 & 0.29 \\
& & & & & \\
0.03 & 0.13 & 0.34 & 0.58 & 0.57 & 0.51 \\
0.16 & 0.22 & 0.54 & 0.85 & 0.81 & 0.59 \\
0.14 & 0.34 & 0.82 & 1.21 & 1.18 & 0.96 \\
0.26 & 0.77 & 1.33 & 2.13 & 2.24 & 1.77 \\
0.20 & 1.15 & 1.75 & 2.33 & 1.97 & 1.84 \\
0.26 & 1.28 & 2.87 & 4.77 & 4.35 & 5.14 \\
0.30 & 3.52 & 3.46 & 4.05 & 3.63 & 3.88
\end{tabular}


Table 3. Relative risks of divorce of Swedish women in first marriages

Hazard model with unobserved heterogeneity term (add woman's parity as an interaction factor with childbearing history)

\begin{tabular}{ll}
\hline woman's age at marriage & \\
\hline $16-19$ & 8.63 \\
$20-23$ & 2.81 \\
$24-28$ & 1.00 \\
$29-35$ & 0.47 \\
$36-49$ & 0.23
\end{tabular}

indicator of woman's pregnancy at marriage formation

$\begin{array}{ll}\text { woman not pregnant } & 1.00 \\ \text { pregnant with common child } & 1.69 \\ \text { of the union } & \end{array}$

pregnant with stepchild to the $\quad 4.08$

husband

\section{Child bearing history of the spouses}

Woman of Parity 0

no premarital children

with premarital children of:

m-type

Woman of parity 1

no premarital children with premarital children of:

c-type

m-type

c-m-mixture

w-type

n. $\mathrm{a}=$ not applicable.

3.50

no common child born after the current marriage formation

n. a

1.27

n.a

1.79

4.40 common child born after the current marriage formation age of the youngest child (years)

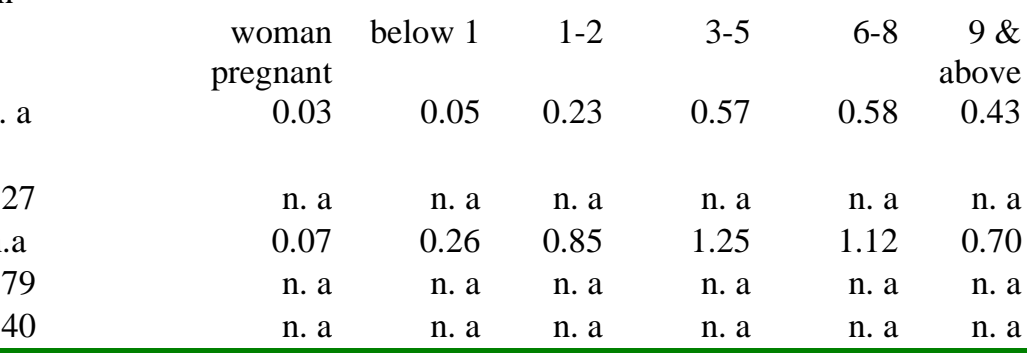


Table 3. (Continued.)

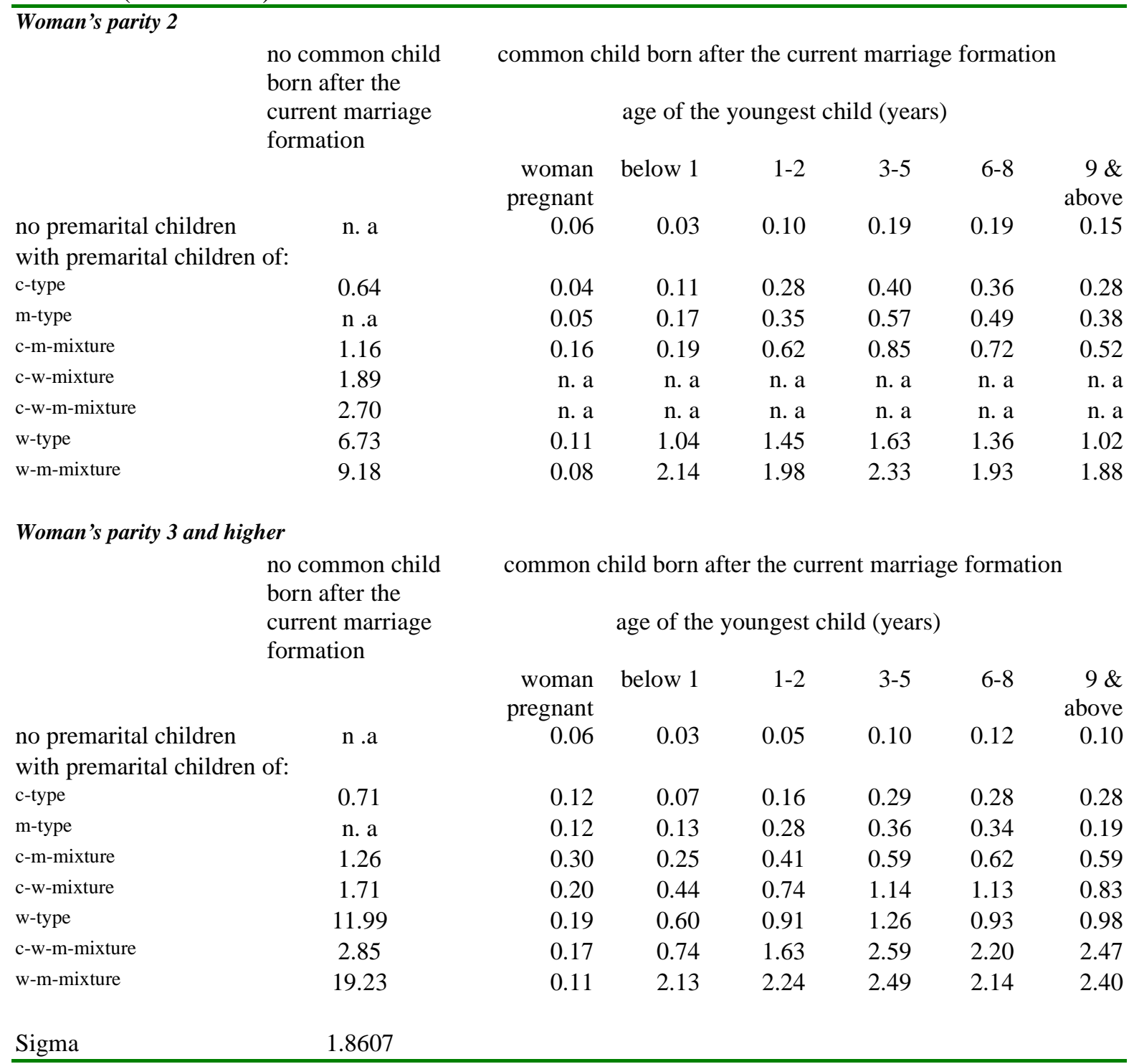

n. a. = not applicable. 


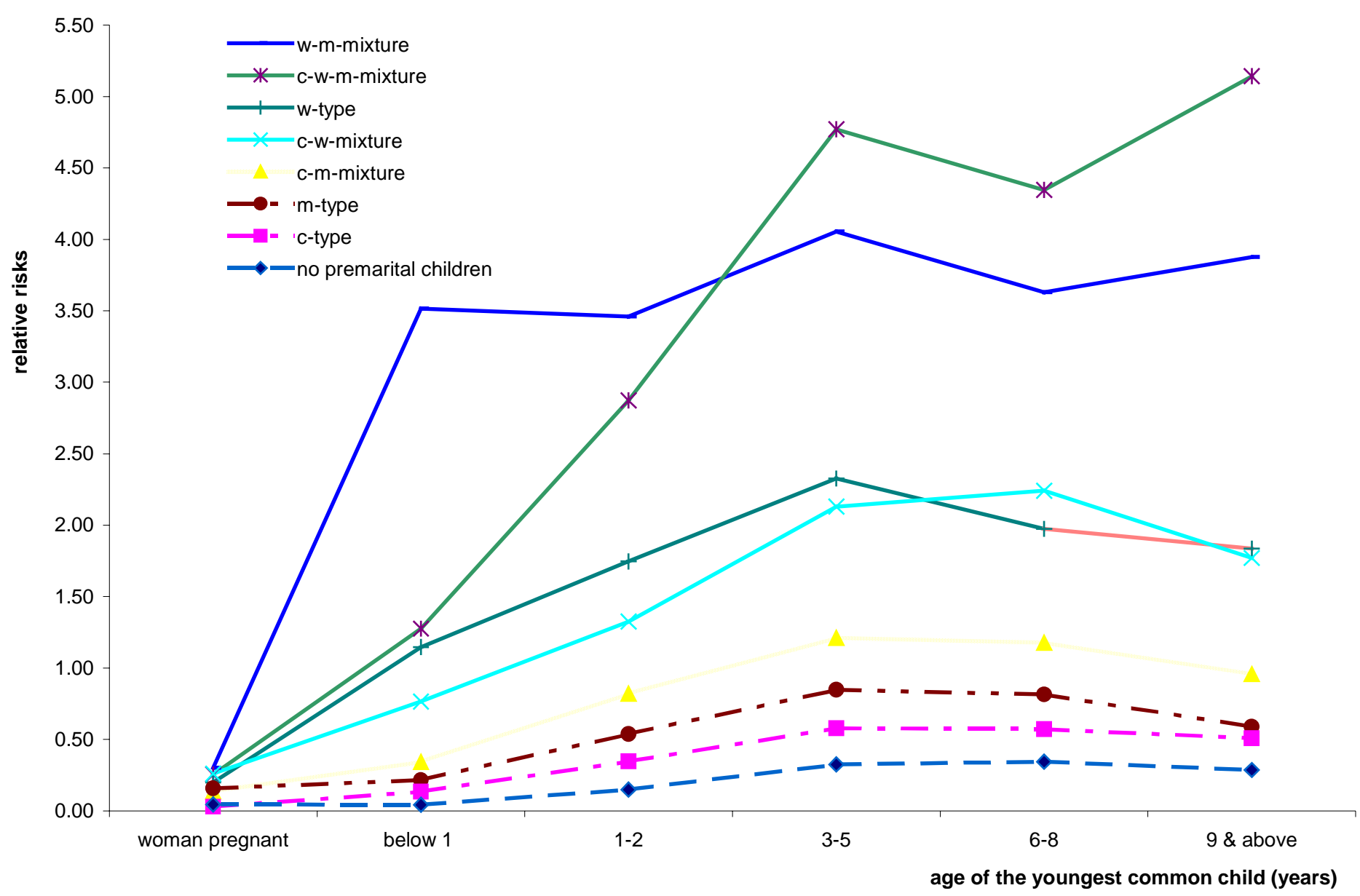

Figure 1a. Divorce risks according to the age of the youngest common child, separately according to parenthood of any premarital children. 


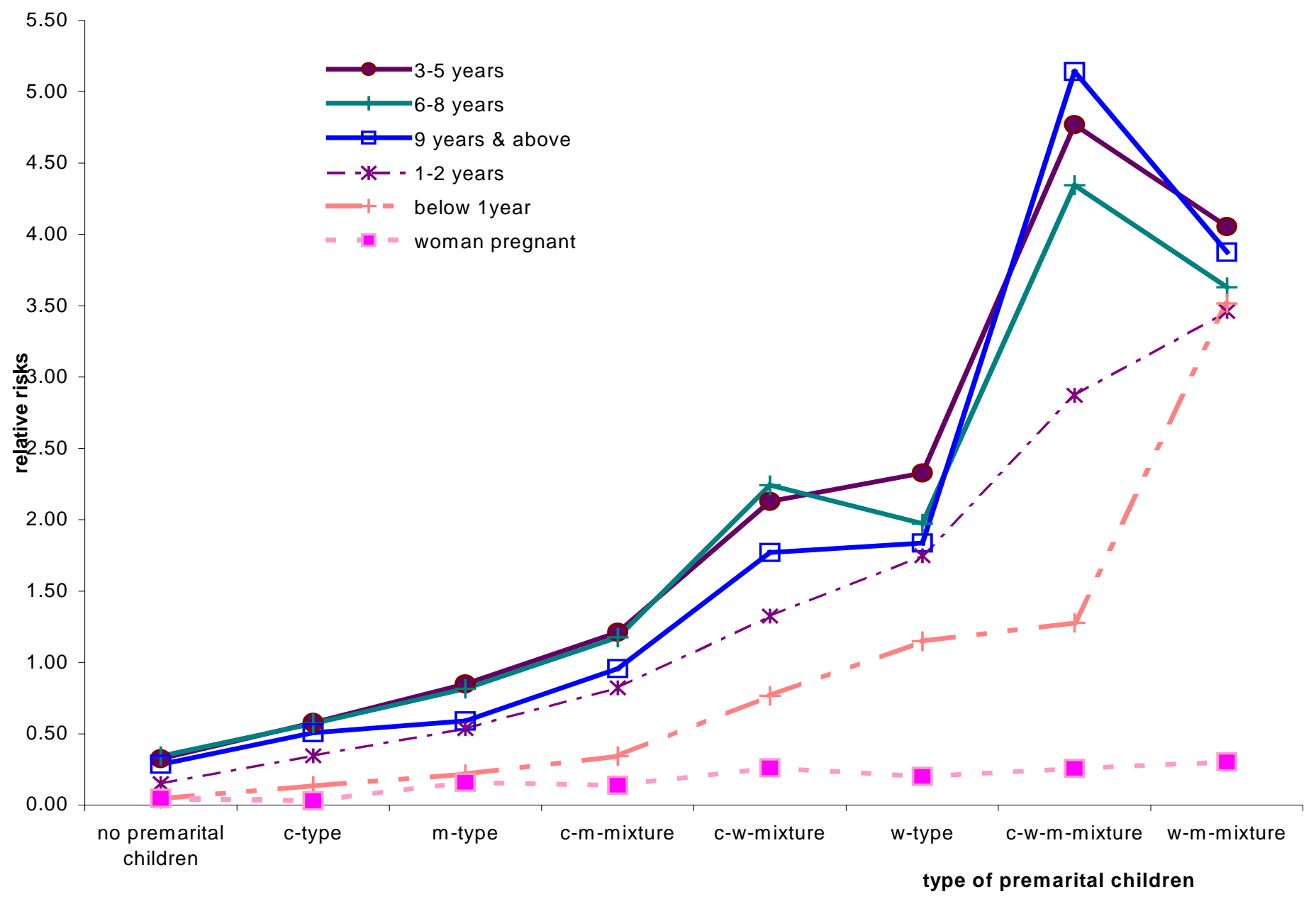

Figure 1b. Divorce risks according to the type of premarital children, separately according to age of the youngest common child. 


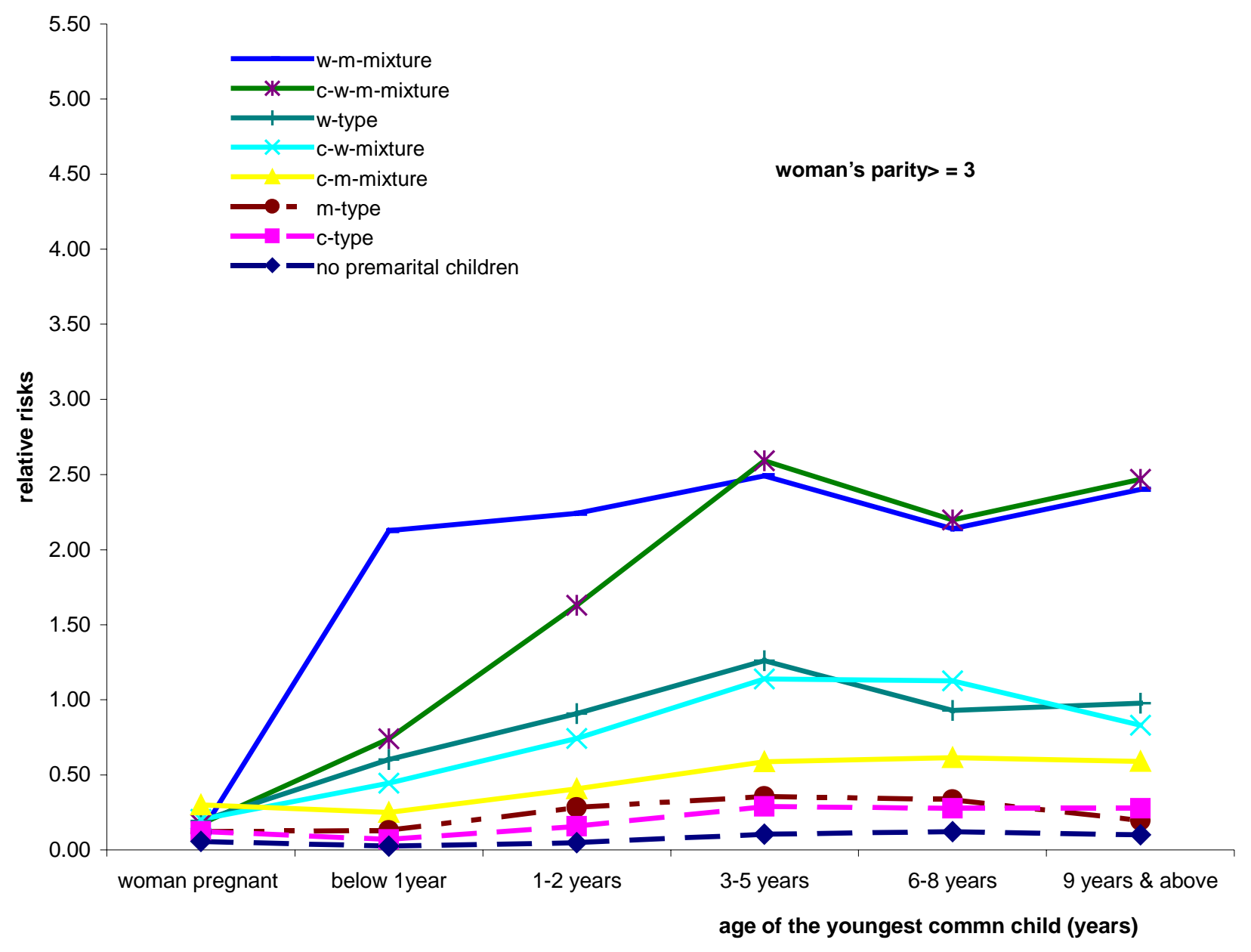

Figure 2a. Divorce risks according to the age of the youngest common child, separately according to parenthood of any premarital children. Woman's parity $>=3$. 


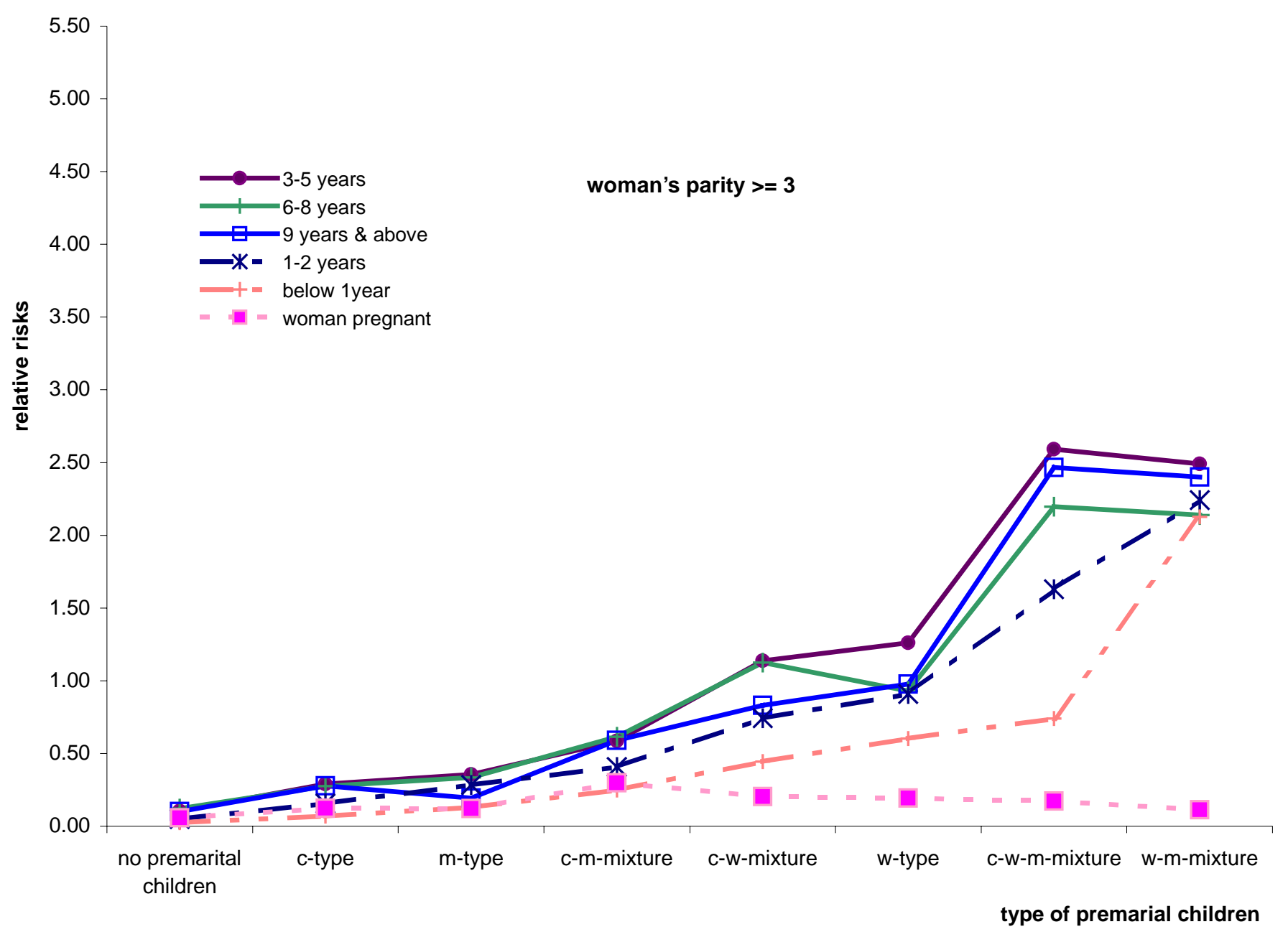

Figure 2b. Divorce risks according to the type of premarital children, separately according to age of the youngest common child. Woman's parity $>=3$. 


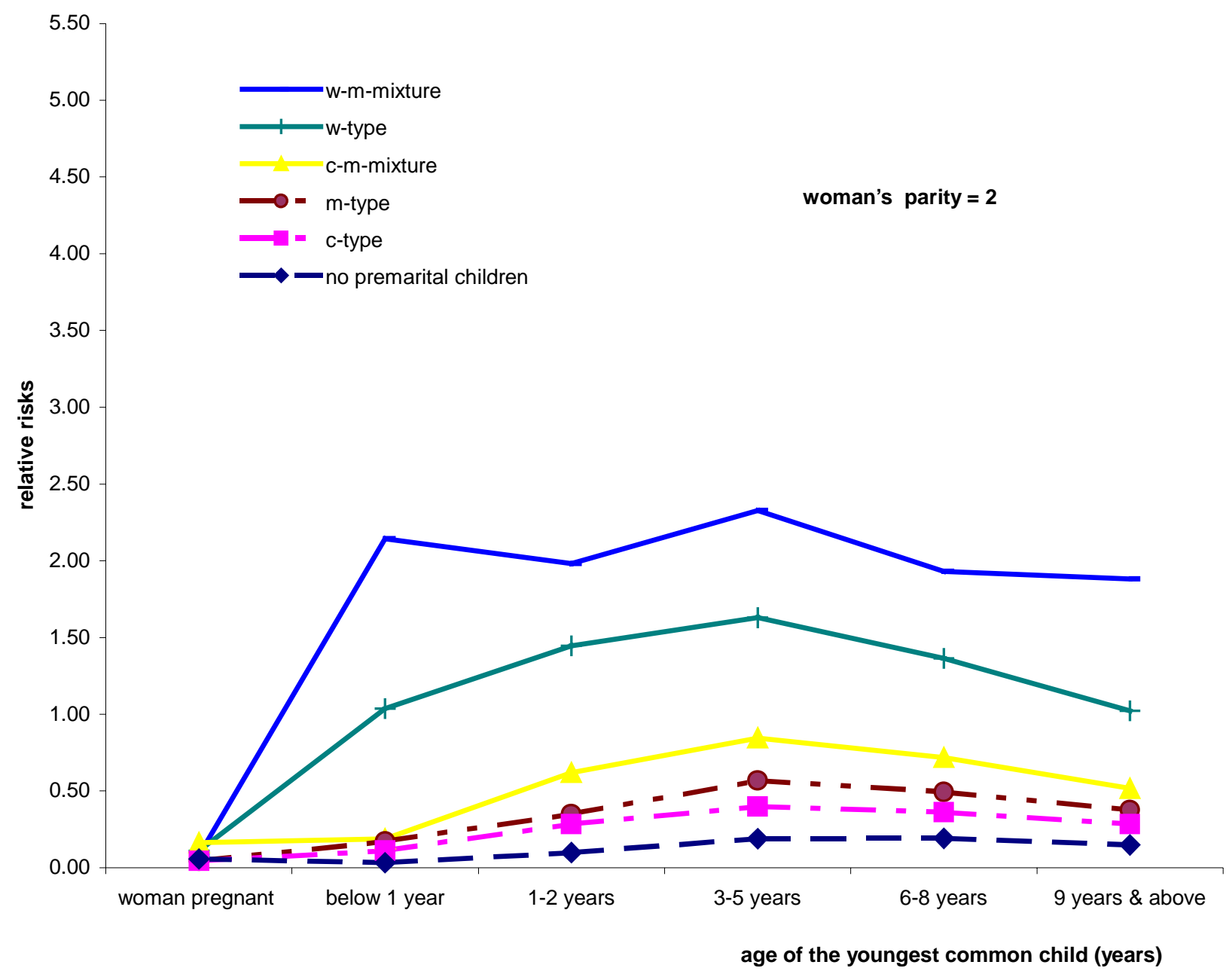

Figure 3a. Divorce risks according to the age of the youngest common child, separately according to parenthood of any premarital children. Woman's parity $=2$. 


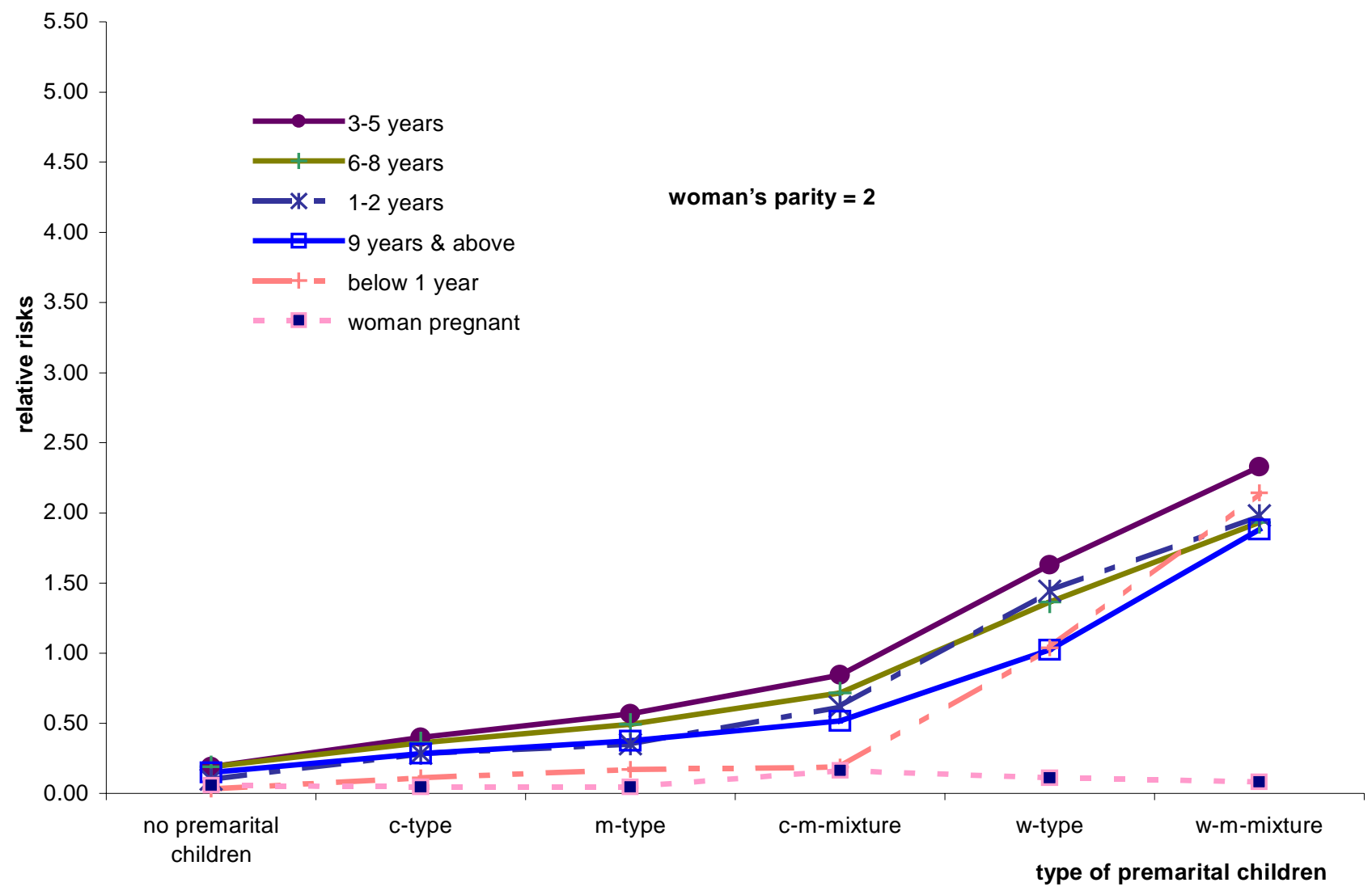

Figure 3b. Divorce risks according to the type of premarital children, separately according to age of the youngest common child. Woman's parity $=2$. 


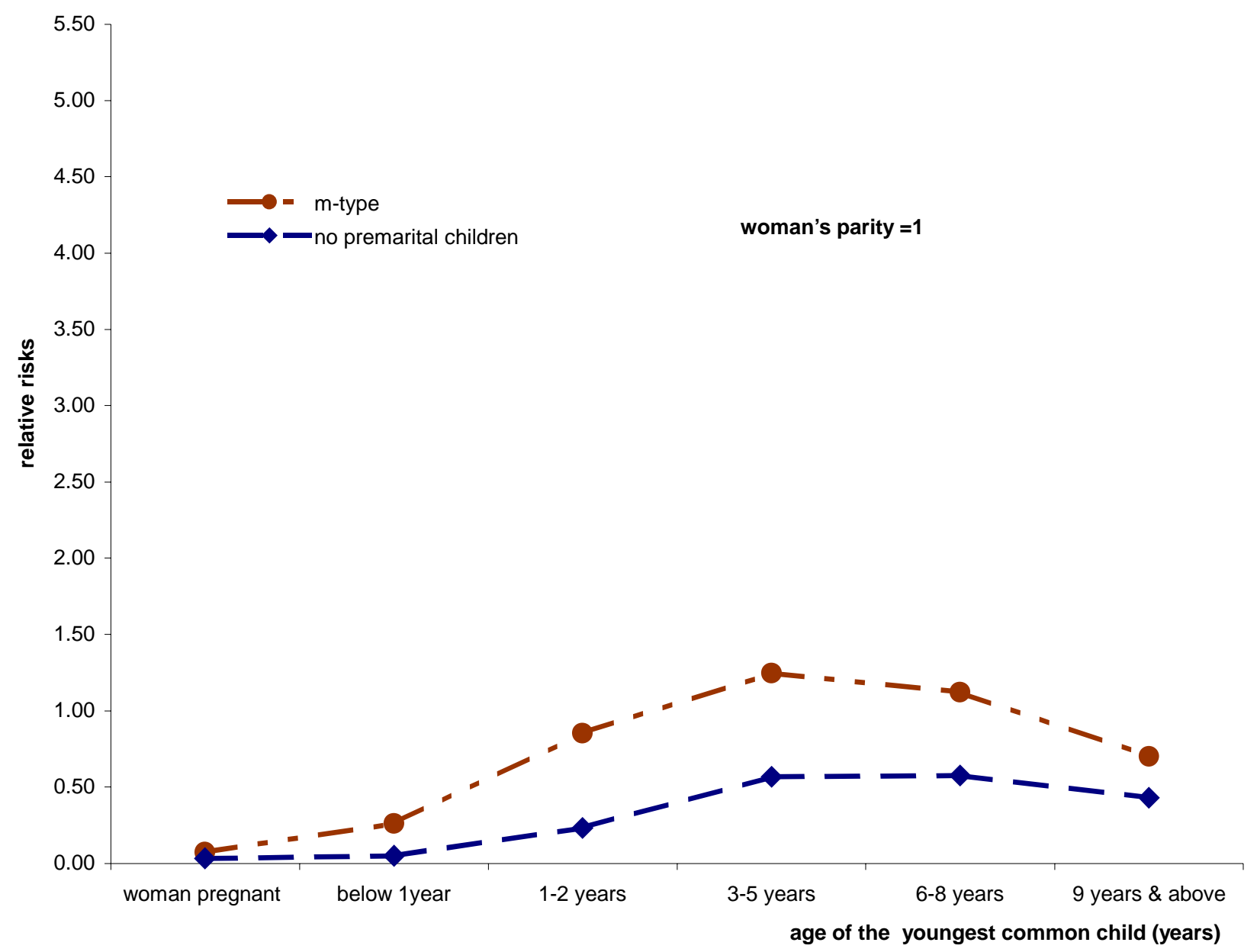

Figure 4. Divorce risks according to the age of the youngest common child, separately according to parenthood of any premarital children. Woman's parity $=1$. 